\title{
COLOMBIA Y LA EDUCACIÓN DEL SIGLO XXI ¿UNA ESCUELA POSTMODERNA?
}

\author{
COLOMBIA AND XXI CENTURY EDUCATION \\ A POST MODERNIST SCHOOL?
}

\author{
Mariana Valencia Leguizamón \\ Daniel Rodríguez León*
}

\author{
Valencia L. Mariana, Rodríguez L. Daniel. Sophia N 7 - 2011. ISSN: 194-8932 Págs. 20-27. \\ Recepción: Mayo 26 de 2011 \\ Aceptación: Julio 5 de 2011
}

\begin{abstract}
Si los libros no sirven para comprender el mundo y para repensar y enfrentar los problemas cotidianos y prácticos, entonces los libros son cosas inútiles.
\end{abstract}

Arreola

\section{RESUMEN}

El presente artículo constituye una reflexión teórica sobre la necesidad de re-pensar la escuela como institución social en virtud del lugar que podría ocupar en ella el maestro Colombiano. Para ello, se proponen cuatro momentos que entretejen, a nuestra manera de ver, el contexto y las razones del problema. La inestabilidad de la relación modernidad-postmodernidad desde Gianni Vattimo constituye el primer estadio como contexto socioculural de la escuela en el siglo XXI. En segundo lugar, recordamos la ruptura entre universidad y sociedad denunciada por Durkheim en el contexto Francés, y relacionada aquí a manera de analogía. En el tercer momento, planteamos la relación problemática entre saber y poder desde Lyotard $y$, finalmente, intentamos perfilar las responsabilidades del maestro colombiano a la luz de las tres dificultades (sub-temas del texto) anteriores

\section{PALABRAS CLAVE}

Educación, modernidad, postmodernidad, maestro, saber, poder, universidad.

ABSTRACT

This article is a theoretical reflection on the urge of rethinking the school as the social scenario where teachers evolve. For this purpose, at our sight, four elements are intertwined as the context and the reason for the situation itself. The unbalance in the relation between the modern and post modernist approaches which according to Gianni Vattimo constitutes the first step as the XXI century socio cultural context of the school. Secondly, we remember the rupture between university

* Especialistas en enseñanza de la literatura, estudiantes de Maestría en Ciencias de la Educación, con énfasis en Didáctica de la Lengua Materna y la Literatura (tercer semestre), Miembros del grupo de investigación DILEMA de la Universidad del Quindío, docentes del programa de Español y Literatura de esta misma universidad. marianavalencia1@hotmail.com Carrera 15 calle 12 Norte, Armenia, Quindío, Colombia. 
and society reported by Durkheim within the French context which is related here as an analogy. Thirdly, we state, the problematic relation between knowledge and power from Lyotard perspective, and finally we try to outline the responsibilities of Colombian teachers to the light of these three previous statements.

KEY WORDS

Education, modernism, postmodernism, teacher, knowledge, power, college.

\section{INTRODUCCIÓN}

Colombia, como muchos otros lugares del mundo, continúa en la búsqueda de su propia identidad. Una identidad que hoy no es posible construir ni reconocer sino en la relación permanente e inestable con los otros, con el contexto global, con "lo otro". Éste principio de alteridad, de diálogo, implica el encuentro con el pasado, con los errores y los aciertos de quienes han construido el país en cadenas temporales a veces imposibles de rastrear, pero de cuyas acciones somos registro y producto. Es difícil, por lo tanto, desligarnos de nuestra tradición, pero es más difícil aún, creer que la historia es una única historia.

El desarrollo de un pueblo es, a la vez, el desarrollo de su educación, de sus costumbres y creencias, de sus miedos, de sus victorias, pero también de sus fracasos. Es necesario reconocer que la educación no es una tarea exclusiva de la escuela y que, en ocasiones, ésta es la que menos influye en dicha labor. Somos parte de un híbrido en el que apenas encajamos y nos movemos como grupo en medio de muchos grupos. Por ello, la escuela está en la obligación de reconocerse como una institución educativa, dentro de muchas otras que influyen, a veces sin proponérselo, en la educación de una cultura como la nuestra. Así las cosas, pareciera necesario preguntarnos por el tipo de educación que ha tenido Colombia y que requiere.

Dada la amplitud del problema nos limitamos a proponer, antes que una respuesta, una descripción limitada de algunas posturas que creemos importantes en la discusión y que planteamos aquí bajo el supuesto de que hace falta re-pensar la escuela colombiana del presente siglo y la figura del maestro como individuo y como institución. Para lograrlo, partimos de una estructura textual basada en los siguientes cuatro ejes temáticos.
En primer lugar, abordamos, a manera de introducción, el paso de la modernidad a la postmodernidad desde las implicaciones históricas señaladas por Gianni Vattimo (1990) en el texto: Posmoderno: ¿una sociedad transparente? En segundo lugar, se propone una descripción de la educación superior francesa en la modernidad, como la concibiera Durkheim (1990), y su posible relación con el contexto de la educación superior colombiana en la actualidad. En tercer lugar, se plantean algunas implicaciones de la relación saber-poder en la sociedad postmoderna descrita por Lyotard (2009) en La condición postmoderna y, finalmente, en el cuarto apartado se pretende tejer una propuesta de reflexión pedagógica, a partir de los presupuestos de las facultades de educación en Colombia y la actuación de un maestro que se ubica a medio camino entre la modernidad y la postmodernidad.

\section{DE LA MODERNIDAD A LA POSTMODERNIDAD}

Al parecer, la crisis del proyecto moderno trajo consigo varias implicaciones. De un lado, la insuficiencia de las empresas humanas basadas en principios de totalidad unitaria y; del otro, la fragmentación del centro de poder alimentada desde los flujos indiscriminados de información, mass media. Con respecto a la primera, resulta iluminadora la postura de Gianni Vattimo (1990) a propósito del tema "[...] la condición para concebir la historia como realización progresiva de la humanidad auténtica estriba en que pueda ser vista como un proceso unitario [...] Pues bien, la modernidad [...] se acaba cuando -debido a múltiples razones- deja de ser posible hablar de la historia como algo unitario" (Vattimo; 1990, 74)

Se advierte desde la cita anterior el reconocimiento de la historia como una operación silenciadora de voces. Un ejercicio de selección ejecutado por los discursos dominantes que, dada su condición, eligen de lo ocurrido, aquello que resulta más 
apropiado, más conveniente a sus propósitos. Dicho sea de paso, que a esta posición política, por darle un nombre, subyace el contexto completo de la sociedad occidental. Tanto la modernidad como la postmodernidad se enmarcan en el "desarrollo" de la sociedad occidental. De la "superación" del teocentrísmo, en el primer caso; y el declive de la empresa moderna, en el segundo.

De vuelta a las implicaciones de este complejo paso histórico, resulta imprescindible la alusión a los mass media como fenómeno comunicativo, social, cultural e incluso político. Vattimo titula su texto mediante un interrogante que alude a la transparencia de esta sociedad y, al respecto, señala: "[...] en el nacimiento de una sociedad posmoderna los mass media desempeñan un papel determinante; [...] éstos caracterizan tal sociedad no como una sociedad más "transparente", más consciente de sí misma, sino como una sociedad más compleja, caótica incluso; y [...] que precisamente en este "caos" relativo residen nuestras esperanzas de emancipación" (Vattimo; 1990, 78)

Contra los pronósticos de algunos pensadores para quienes el desarrollo de estos medios de comunicación traería la homogeneidad de los pueblos e incluso posibilitaría intervenciones políticas totalitarias ${ }^{1}$, Vattimo superpone lo que parece fue el verdadero efecto: la consolidación de la pluralidad. La naciente ola de minorías que han tomado la palabra para reivindicar sus derechos 0 , al menos manifestar su desacuerdo, constituirían, primero en Estados Unidos y luego en otros lugares del mundo, la movilización de agentes marginales que iniciarían, así, un desplazamiento grupal hacia el centro.

En consecuencia, esta diversidad cultural, que daría carta abierta a otros discursos hasta entonces silenciados, no es ajena a la anterior imposibilidad de considerar la historia como una verdad única y absoluta, sino que, por el contrario, implica una nueva dimensión re-evaluadora del hombre blanco europeo como la regla de medida general. Sin embargo, la presencia inevitable del mundo prefabricado que circula por los medios de comunicación de masas supone

1 "[...] a través de la distribución de Slogans, propaganda política y comercial; y visiones estereotipadas del mundo" (Vattimo; 1990, 79) una transmutación de lo real y la tipificación de algunos agentes sociales. Para evitar la abstracción exagerada nos remitimos nuevamente a Vattimo: "Por una especie de perversa lógica interna, el mundo de los objetos medidos y manipulados por la ciencia-técnica [...] se ha convertido en el mundo de las mercancías, de las imágenes, en el mundo fantasmagórico de los mass media" (Vattimo; 1990, 83)

Así, resulta inevitable preguntarse qué es lo que se manipula y se convierte en mercancía, en imagen. La respuesta puede ser tan simple como desoladora. Habrá que admitir, no sin cierto escepticismo, que en el mundo mediatizado cualquier cosa puede convertirse en un reflejo maleado de sí misma. Desde los objetos hasta las personas y desde la ciencia hasta el arte. El conocimiento, de hecho, se transfigura y mercantiliza de manera que se convierte, al mismo tiempo, en objeto comercial y fuente de poder. Sobre esta idea volvemos en el tercer eje temático a partir de Lyotard.

Para cerrar esta primera parte y dar paso al segundo pilar temático (la vigencia de Durkheim), quisiéramos aludir a la fuerza con que las ideas hasta aquí expresadas caracterizan nuestro contexto colombiano en tanto cultura híbrida, de orígenes dispersos y con fuerzas mediáticas altamente influyentes. Asimismo, hemos elegido esta introducción gracias al énfasis que se pone en la mercantilización de las instituciones sociales ya que, como veremos más adelante ${ }^{2}$, nos hace falta reconocer a ese maestro en manos de quien se están formando las nuevas generaciones. Unas generaciones influidas por este paso inestable que se torna posmoderno sin abandonar la modernidad.

Filósofos nihilistas como Nietzsche y Heidegger (pero también pragmáticos como Dewey o Wittgenstein), al mostrarnos que el ser no coincide necesariamente con lo estable, fijo y permanente, sino que tiene que ver más bien con el evento, el consenso, el diálogo y la interpretación, se esfuerzan por hacernos capaces de recibir esta experiencia de oscilación del mundo posmoderno como chance de un nuevo modo de ser (quizás, al fin) humano. (Vattimo; 1990, 87)

\footnotetext{
$2 \quad$ En el apartado de cierre.
} 


\section{SOBRE LA VIGENCIA DE DURKHEIM EN LA UNIVERSIDAD COLOMBIANA DEL SIGLO XXI}

"La crisis del proyecto moderno" definida a manera de introducción en el apartado anterior, nos permite ahora centrar la reflexión en una de las instituciones a través de las cuales se advierte, con mayor peligro, dicha crisis: la Universidad. En este sentido, damos paso al segundo pilar temático de la presente reflexión, cuya preocupación principal es, como se ha dicho, re-pensar el lugar de escuela en Colombia. Para ello, nos referimos a un contexto distinto del nuestro, pero en cuya estructura se advierten algunas problemáticas equiparables con la situación actual de nuestra educación superior.

La ponencia presentada en 1900 por Emile Durkheim en el congreso nacional de educación social, y retomada por Fernando Álvarez (2007), plantea un concepto de universidad que entra a re-evaluar el establecido hasta entonces. Allí, se cuestiona la enorme distancia entre la realidad social del país y las preocupaciones internas de la universidad francesa. Al respecto, el autor señala "los cursos se cerraron a los ruidos del exterior a la vez que se aislaban del ambiente social de tal forma que los profesores se privaban a sí mismos de los medios para jugar en la vida general del país el papel al que tenían derecho" (Álvarez, 2007, 84)

Lo anterior, implica reconocer al docente universitario como un actor político consciente o no de su impacto en la dinámica social. Por ello, la relación entre los saberes disciplinares y su capacidad de actuación, constituye para Durkheim una posibilidad de intervención en la estructura misma de la sociedad o, cuando menos, una posibilidad de reflexión al respecto. De allí, puede inferirse la pregunta sobre el tipo de sociedad que se refleja en el discurso y la actuación de estos maestros universitarios y, guardadas las proporciones, podríamos extender esa misma pregunta a nuestra sociedad actual. La respuesta no es de nuestro interés inmediato.

Frente a la preocupación por los límites que aíslan esta universidad de su propio contexto, a comienzos del siglo XX, este autor reconoce dos factores altamente influyentes. La formación moral y el aislamiento sistemático de los maestros de educación básica (primera enseñanza). Con respecto al segundo, se sugiere la inclusión de estos primeros niveles de enseñanza en el trabajo desde la educación superior para consolidar una intervención social que provenga de la escuela en sus diferentes escenarios de acción. En el mismo sentido, se propone la necesidad de vincular los diferentes campos del saber en ejercicios de diálogo que conduzcan al desarrollo cooperativo de las diversas disciplinas. No obstante, este desarrollo tiene ciertas implicaciones en el primer factor: la formación moral.

"[...] no existe vida moral más que cuando el hombre esta asociado a otros hombres; forma con ellos grupos de los que depende, y en cuya vida participa" (Álvarez, 2007, 85) Esta postura sugiere la importancia de generar conciencia colectiva dentro de la misma universidad, de manera que el problema específico de las disciplinas se aborde en virtud del contexto social. Un contexto ignorado y ensordecido; al que no se le reconoce en este diálogo universitario. Tal es la óptica del autor cuando explica la naturaleza del problema al tiempo que esboza una posible solución basada en el reconocimiento del otro y la consolidación de un pensamiento colectivo.

La necesidad de construir colectividad (tanto de actores como de disciplinas) se traduce de varias maneras posibles que el autor observa con detenimiento. En principio, existe un cierto acuerdo entre los pedagogos modernos en ubicar la educación como algo eminentemente individual y, por lo tanto, se asume a la pedagogía como un derivado directo de la psicología. Esta postura es fuertemente rebatida por Durkheim dado que, si bien se ponen en diálogo dos disciplinas de base, su dependencia no es suficiente "[...] el postulado mismo de cualquier especulación pedagógica, al igual que la educación, es algo eminentemente social, por sus orígenes y por sus funciones, [...] la pedagogía depende más estrechamente de la sociología que de cualquier otra ciencia" (Álvarez, 2007, 93)

Más adelante, la relación (o quizás, la oposición) entre naturaleza y educación aparece como una nueva dimensión del vínculo inestable entre la universidad y su contexto social. En este punto se afirma que el hombre hecho por la educación no 
es el hombre hecho por la naturaleza; en tanto que, a este último, no se le ha condicionado para actuar según las necesidades del contexto dentro del cual es formado. De allí, hace falta extender el problema a los criterios para la elección de los contenidos científicos por los que optan, en determinado momento histórico, las universidades.

Al respecto, el profesor Alejandro Álvarez Ga$\operatorname{llego}^{3}$ identifica la dificultad como un asunto no únicamente de contenidos disciplinares y criterios de selección, sino, sobre todo, un problema de forma. Es decir, (en este caso) un problema político:

“La preocupación por la formación de las nuevas generaciones [...] cambia con el tiempo, pero además está atravesada por todos los conflictos de intereses que existen en cada sociedad y en cada momento histórico, incluidos los que provienen de la ciencia. Por eso siempre hay que tener en cuenta los juegos del poder para hablar de pedagogía" (Álvarez; 2003, 297).

Se alude, con lo anterior, a un cierto engranaje de las instituciones sociales del cual la universidad hace parte, pero no llega a ser protagonista. Más bien, pareciera evidente que su desarrollo respondiera, al menos parcialmente, a las fuerzas externas de la institución universitaria.

Con lo dicho en este segundo momento del texto, hemos intentado recoger la lectura que hiciera Durkheim de la universidad francesa a comienzos del siglo pasado, para rastrear, hipotéticamente, la vigencia de algunos de sus planteamientos en el contexto universitario colombiano de la actualidad. Ideas como; la distancia universidad-contexto social; la responsabilidad política del maestro; la no vinculación entre los niveles básicos de escolaridad y la educación superior, la formación moral de los estudiantes y la influencia del poder político del estado en la consolidación y el desarrollo curricular podrían ser, entre otros aspectos, objeto de estudio desde la educación superior de nuestro país. Pasamos ahora al tercer eje temático del

3 "[...] a través de la distribución de Slogans, propaganda política y comercial; y visiones estereotipadas del mundo" (Vattimo; 1990, 79) texto: Lyotard y su lectura del rol del saber en la postmodernidad.

\section{EL SABER EN LA SOCIEDAD POSTMODERNA}

Hemos construido una estructura textual que va del concepto de modernidad puesto en crisis (apartado uno) a la idea de maestro como agente político en la educación superior. Los puntos dos y tres del texto constituyen parte del camino que hace falta recorrer para identificar la necesidad de re-pensar la naturaleza de la escuela en Colombia. Así las cosas, la referencia a Durkheim pretende contextualizar la crisis en el ámbito específico de la educación superior para pasar, a continuación, al reconocimiento de la relación saber-poder en la sociedad postmoderna.

El contexto histórico que lleva a los hombres a la postmodernidad marca de manera profunda su modo de relacionarse con todo cuanto existe, su forma de comprender y de aproximarse al mundo. Si en la modernidad el predominio de la razón se fundamentaba en la esperanza de un mundo mejor, con mejores condiciones de vida para los seres humanos, este ideal se viene abajo tras, por ejemplo, el impacto de las guerras, justificadas precisamente desde la misma razón y llevadas a cabo gracias a los avances técnicos y científicos de la época. Estos aspectos evidencian, de manera lamentable para muchos seres humanos, una relación que tal vez no se había vislumbrado, por lo menos de manera tan clara hasta ese momento, el vínculo entre saber y poder.

No quisiéramos decir con esto que dicha relación no hubiera existido antes, pues es sabido que a lo largo de la historia el conocimiento, en sus diferentes dimensiones, ha sido más asequible a ciertos grupos privilegiados, situación que ha justificado en gran medida el mantenimiento de un orden particular de cosas. Sin embargo, este vínculo, en la postmodernidad adquiere una connotación diferente, más profunda y más oscura si se quiere, en tanto la relación saber-poder es indirectamente proporcional a la relación saberbeneficio común. De allí que la veracidad del saber quede en entredicho puesto que, al estar al servicio del poder, deberá encargarse de legitimarlo, más allá de la relación que sostenga con la verdad. 
Las consecuencias de esta proporción son evidentes; el deterioro del planeta, la desigualdad en todas sus dimensiones, las guerras constantes, entre otros, son prueba de que el saber, lejos de ser un camino a la verdad se ocupa, cada vez más, de demostrar "verdades" que, aunque contradictorias en muchos casos y completamente improbables en otros, se presentan de manera tan real que terminan por generar, para algunas personas, un estado alterado de conciencia que los lleva a confundir, como diría Carlos Lomas, las imágenes de lo real con la realidad de las imágenes; cuando no a la sensación de un mundo paralelo al real, sin poder determinar con mucha precisión cuál es el primero y cual el segundo.

En la generación de este efecto los medios masivos de comunicación, que al igual que la ciencia, se encuentran al servicio del poder, ocupan un lugar importante puesto que son los encargados de demostrar y difundir el sin número de "verdades" que orientan el pensamiento y la acción del hombre postmoderno. "[...] no hay prueba ni verificación de enunciados, ni tampoco verdad, sin dinero. Los juegos del lenguaje científico se convierten en juegos ricos, donde el más rico tiene más oportunidades de tener razón. Una ecuación se establece entre riqueza, eficiencia y verdad." (Lyotard, 2006: 84)

\section{UNA MIRADA LOCAL (EL PROBLEMA EN EL CONTEXTO COLOMBIANO)}

Así las cosas, valdría la pena pensar, como lo hiciera en su momento Durkheim, a propósito del papel de las universidades en la educación social francesa, en el lugar que debería ocupar y en el carácter que debería tener hoy la educación colombiana. Sin embargo, dada la amplitud y profundidad que dicha reflexión exige, intentamos ahora aproximarnos a un objeto mucho más delimitado. A saber, el papel de las facultades de educación en nuestro país, puesto que, si bien existe la convicción de que la escuela no debe ser el único estamento encargado de educar a los ciudadanos en todas sus dimensiones, como dijera Peter Drucker (1995), hoy, y hace ya bastante tiempo, se hace necesaria una formación multidimensional que permita a los futuros docentes asumir la responsabilidad que su tarea requiere.
En una sociedad con las características anteriormente descritas, en la que el saber ha desplazado su ruta de la búsqueda de la verdad hacia el encuentro con el poder, se hace cada vez más urgente la reivindicación de la educación y con ella la re-valoración del maestro. Para ello, no basta con ser conscientes del problema ni con el simple ejercicio de la voluntad. Aunque ambos factores son indispensables, deben estar acompañados de una formación política, social, humana y disciplinar, es decir interdisciplinar, que permita afrontar los avatares de educar en un contexto como el nuestro (como se propone en los documentos oficiales) ${ }^{4}$. De allí que, aún más de cien años después, consideremos válida la afirmación de Durkheim al decir que no hay otra forma de concebir la educación que no sea desde lo social.

Por este motivo, consideramos que la investigación debe ocupar un lugar fundamental en las facultades de educación colombianas, donde se conciban proyectos que tengan origen en situaciones reales y frecuentes en las comunidades, de manera que sus resultados trasciendan los anaqueles de las bibliotecas y entren a hacer parte de la dinámica social, cultural y educativa de las diferentes instituciones sociales. De allí, la importancia de la conexión permanente entre universidad y centros educativos de enseñanza media y básica, porque de estos últimos salen algunas de las situaciones que requieren mayor atención. Problemas comunes como, por ejemplo, los vacíos disciplinares, pedagógicos y didácticos que alimentan y pueden seguir alimentando las investigaciones adelantadas por diferentes grupos y que, de manera cooperativa con los docentes a mediano o largo plazo, podrán aportar luces a la práctica educativa. La vinculación de los futuros docentes a este tipo de procesos permite su aproximación a los contextos reales de enseñanza y aprendizaje, lo que, necesariamente, favorece y puede orientar su formación.

En el mismo sentido, compete a las facultades de educación diseñar currículos que permitan a

\footnotetext{
$4 \quad$ Ley 115 de 1994, ley general de la educación en Colombia. ARTÍCULO 10. OBJETO DE LA LEY. La educación es un proceso de formación permanente, personal, cultural y social que se fundamenta en una concepción integral de la persona humana, de su dignidad, de sus derechos y de sus deberes.
} 
los docentes en formación establecer la conexión entre saberes disciplinares, pedagógicos y didácticos, ya que sólo este tipo de procesos permiten la coexistencia necesaria de los discursos científico, psicológico y social; el primero de ellos referido a los saberes propios de cada disciplina; el segundo, relacionado con la concepción del estudiante como sujeto que aprende; y el tercero, ocupado directamente del contexto o mejor, de los contextos tanto del estudiante como en los que se desarrolla el acto de enseñanza y aprendizaje. La concienciación de este vínculo, por parte del maestro, puede generar una mirada más favorable de la escuela y de la educación en los niños y jóvenes que asisten a las aulas de educación básica y media, puesto que en la medida que ellos identifican la relación entre lo que ya conocen (contexto significativo interno) y la utilidad que puede tener lo que aprenden en el marco en que actúan (contexto significativo externo) podrán ver en la escuela algo más que contenidos aislados e inútiles que terminan por entorpecer tanto la motivación como la adquisición de conocimiento.

Ahora bien, el diálogo entre los discursos anteriormente mencionados no se da de manera abstracta; sino que son las actividades planeadas por los docentes las que los encarnan; actividades específicas para grupos específicos. Si tenemos en cuenta los discursos psicológico y sociológico, salta a la vista que la educación no es un proceso genérico; de allí la importancia de la creatividad que, junto con un conocimiento amplio de sus estudiantes, debe acompañar al docente en el diseño y la planeación de diferentes actividades que, si bien están orientadas a la adquisición de ciertos contenidos conceptuales, no es éste el único propósito que las ilumina, junto a ellos se encuentran los contenidos procedimentales y los actitudinales, ambos de vital importancia en tanto fortalecen la autonomía, la autoestima y el autoconcepto, por un lado, y, por otro, avanzan en pro del reconocimiento de sí mismo y del otro.

En todo esto juega un papel esencial la persona más experta, que ayuda a detectar un conflicto entre lo que ya se conoce y lo que hay que saber, que contribuye a que el alumno se sienta capaz y con ganas de resolverlo, que plantea el nuevo contenido como un reto interesante, la resolución del cual tendrá utilidad, que interviene de forma ajustada en los progresos y las dificultades que el alumno ma- nifiesta, apoyándolo, y previendo, a la vez, la actuación autónoma del alumno. Es un proceso que no sólo contribuye a que el alumno aprenda unos contenidos, sino que también hace que aprenda a aprender y que aprenda que puede aprender. Su repercusión no se limita a lo que el alumno sabe, sino que influye en lo que sabe hacer y en la imagen que tiene de sí mismo.

(Zabala, 2002: 64)

A propósito de la anterior cita preguntamos entonces ¿quién es esa persona más experta a la que se refiere Zabala? No es difícil responder que el docente. En este mismo orden de ideas podemos preguntar ¿Cómo y dónde aprende el docente a desenvolverse de la manera que el autor sugiere? Aquí la respuesta nos conduce a la idea que venimos desarrollando desde párrafos anteriores; son las facultades de educación las que deben capacitar a los docentes para afrontar los complejos procesos de enseñanza y aprendizaje en pro de un mejoramiento tanto en la adquisición de conocimientos como de la libertad que una buena práctica, orientada a la autonomía puede ofrecer. Al respecto Juan José Arreola, en los lineamientos curriculares de lengua castellana señala: "No hay novedad ni reforma si no nos convertimos en verdaderos autodidactas. Todo individuo está potencialmente en capacidad de penetrar a los universos más complejos del conocimiento si tiene la voluntad libre de indagar y descubrir." (Lineamientos curriculares de lengua castellana,1998).

Indagar y descubrir el mundo del que hacemos parte, y cuyo interior se muestra problemático y simple al mismo tiempo. Como en la crisis de la empresa moderna que Vattimo mostrara como una realidad alterada que rehúsa definirse. Como la universidad encapsulada en sí misma y señalada por Durkheim, o la mutación entre la escuela y la empresa que hace del conocimiento un híbrido amorfo entre saber y poder. Como la escuela bien intencionada que prepara a sus estudiantes para lo que tal vez no se necesita, y ¿qué se necesita? He aquí la responsabilidad de las facultades de educación. ¿Qué podría constituir un verdadero aporte en la construcción de una educación mejor para nuestro país? No lo sabemos, a ciencia cierta. Pero sabemos que hace falta pensar y re-pensar nuestra escuela y sus maestros. Los maestros de un país que ha sido pensado ya muchas veces desde el vacío borroso que une y separa la modernidad de la postmodernidad. 


\section{REFERENCIAS BIBLIOGRÁFICAS}

Alipedo, G. (1994) Didáctica de las ciencias del lenguaje. Aportes y reflexiones. Buenos Aires. Paidós.

Álvarez, A. (2003) La pedagogía y las ciencias, historia de una relación. Magisterio. Bogotá.

Álvarez, F. (2007) Karl Marx, Max Weber y Emile Durkheim. Sociología y Educación. Morata. Madrid.

Drucker, P. (1995) Su visión sobre: La administración. La organización basada en la información, la economía, la sociedad. Bogotá. Norma.

Ministerio de Educación Nacional (1994) Ley general de educación. Bogotá.

Ministerio de Educación Nacional (1998). Lineamientos curriculares de lengua castellana. Santafé de Bogotá.

Ministerio de Educación Nacional (2003). Estándares básicos de Lenguaje para la Educación Básica y Media. Bogotá.

Lyotard, J-F (2006) La condición postmoderna. Madrid. Cátedra.

Vattimo, G. (1990). Posmoderno: ¿Una sociedad transparente? Barcelona. Paidós.

Zabala, A. (2002). La práctica educativa. Cómo enseñar. Barcelona. Graó. 